Brit. Heart J., 1964, 26, 832.

\title{
POST-VALVULAR STENOSIS OF THE PULMONARY ARTERY AND ITS BRANCHES
}

\author{
BY \\ SAMUEL ORAM, NORMAN PATTINSON, AND PAGET DAVIES \\ From the Cardiac Department, King's College Hospital, London, and the Radiodiagnostic Department, Middlesex \\ Hospital, London
}

Received April 9, 1964

Though stenosis of the trunk and branches of the pulmonary artery has long been reported at necropsy (Maugars, 1802; Fürst, 1878; Schwalbe, 1909; Oppenheimer, 1938), the disorder was thought to be extremely rare. During the past decade, however, it has been recognized more often due to the introduction of cardiac catheterization and selective angiocardiography (Möller, 1953; Coles and Walker, 1956; Smith, 1958; Luan et al., 1960). In a series of 1650 cardiac catheterizations 60 examples of bilateral multiple stenosis of the pulmonary artery were reported by Agustsson et al. (1962), while in the same year Bell et al. were able to find 14 examples among 175 patients with congenital heart disease.

However, angiocardiographic confirmation of the anatomy has not always been sought, and we think that the diagnosis must remain in doubt in those where the gradient as measured by catheterization has been small and not subsequently confirmed radiologically.

It is our purpose to analyse the published examples, to propose a classification (Table I), to describe the clinical picture, and to present details of 9 additional patients. Of these, 6 had both cardiac catheterization and angiocardiography. Catheterization revealed the diagnosis in all, but angiocardiography demonstrated the stenosis in only 4 . In 2 others angiocardiography alone was performed and the diagnosis revealed in both. In one cardiac catheterization only was carried out and a pulmonary arterial gradient was demonstrated.

To date 202 patients with post-valvular stenosis of the pulmonary artery and its branches have been reported, but we have analysed only those where adequate descriptions of both the clinical features and investigations have been given. To these 108 we have added details of a further 9 patients of our own making a total of 117 (Table II).

\section{CASE REPORTS}

Patient 1. A girl, aged 4 years, was referred in April 1959 as her family doctor had heard a murmur during incidental examination. At the age of 14 months a cleft palate had been repaired. She had never been as well developed as her sibs. She became dyspnœic on moderate exertion, but there was no history of cyanosis.

Examination showed a small child (height, $36 \mathrm{in}$. $(90 \mathrm{~cm}$.); weight, $28 \mathrm{lb} .(12.7 \mathrm{~kg}$.)) with a continuous murmur heard all over the chest, and best heard about 1 in. to the left of the spine posteriorly near the angle of the scapula. The blood pressure was $90 / 60 \mathrm{~mm}$. $\mathrm{Hg}$. The electrocardiogram was within normal limits for the age while the chest radiograph showed pleonæmic lungs with a prominent pulmonary artery and right ventricle. At cardiac catheterization on February 15, 1960 the catheter passed across an atrial septal defect, through which there was a left-to-right shunt of 0.31 . per minute (Table III). The catheter could not be 
TABLE I

Classification of Post-valvular Stenosis of the Pulmonary Artery and Branches

\begin{tabular}{|c|c|c|c|}
\hline $\begin{array}{l}\text { Congenital } \\
\text { Acquired }\end{array}$ & . & $\left.\begin{array}{l}\text { I*: Multiple peripheral stenoses with or without stenosis of } \\
\text { right or left main branch } \\
\text { II: Stenosis at bifurcation of pulmonary trunk } \\
\text { III: Stenosis of pulmonary trunk } \\
\text { IV: Combinations of I, II, and III } \\
\text { Extramural (e.g. tumour) } \\
\text { Intramural (e.g. thrombus or embolus) }\end{array}\right\}$ & $\begin{array}{l}\text { (a) Isolated } \\
\text { (b) Combined with other } \\
\text { congenital cardiac } \\
\text { lesions }\end{array}$ \\
\hline
\end{tabular}

* Rarely, in type I only, the left main branch may be absent.

TABLE II

Anatomical Type of Pulmonary Arterial Stenosis and Associated Lesions According to Age and Sex in 117 PATIENTS

\begin{tabular}{|c|c|c|c|c|c|c|c|c|c|c|c|c|c|c|}
\hline \multirow{2}{*}{$\begin{array}{c}\text { Age } \\
\text { (yr.) }\end{array}$} & \multicolumn{3}{|c|}{ Sex } & \multirow[t]{2}{*}{ I } & \multirow[t]{2}{*}{ II } & \multirow[t]{2}{*}{ III } & \multirow[t]{2}{*}{ IV } & \multicolumn{7}{|c|}{ Associated anomalies } \\
\hline & $\mathbf{M}$ & $\mathbf{F}$ & $\begin{array}{c}\text { Not } \\
\text { stated }\end{array}$ & & & & & PS & AS & ASD & VSD & PDA & Fallot & Complex \\
\hline \multirow[t]{3}{*}{$\begin{array}{c}0-4 \\
5-9 \\
10-14 \\
15-19 \\
20-24 \\
25-29 \\
30-34\end{array}$} & $\begin{array}{r}19 \\
17 \\
7 \\
7 \\
2 \\
1\end{array}$ & $\begin{array}{r}18 \\
15 \\
9 \\
5 \\
1 \\
2 \\
1\end{array}$ & $\begin{array}{r}10 \\
2 \\
1\end{array}$ & $\begin{array}{c}23 \\
14 * \\
4 \\
6 \\
1 \\
1\end{array}$ & $\begin{array}{r}19 \\
16 \\
7 \\
2 \\
2 \\
3\end{array}$ & $\begin{array}{l}3 \\
1 \\
4 \\
3\end{array}$ & $\begin{array}{l}\mathbf{2} \\
\mathbf{3} \\
\mathbf{2} \\
\mathbf{1}\end{array}$ & $\begin{array}{l}8 \\
1 \\
1\end{array}$ & $\begin{array}{l}2 \\
2\end{array}$ & $\begin{array}{l}1 \\
1 \\
1 \\
1\end{array}$ & $\begin{array}{l}4 \\
2 \\
2 \\
1\end{array}$ & $\begin{array}{l}2 \\
1 \\
1\end{array}$ & $\begin{array}{l}8 \\
2 \\
6 \\
1\end{array}$ & $\begin{array}{c}10 \\
11 \dagger \\
1 \\
1 \\
1\end{array}$ \\
\hline & 53 & 51 & 13 & 49 & 49 & 11 & 8 & 10 & 4 & 4 & 9 & 4 & 17 & 24 \\
\hline & \multicolumn{3}{|c|}{117} & \multicolumn{4}{|c|}{117} & \multicolumn{7}{|c|}{72} \\
\hline
\end{tabular}

* Three with absent left main branch of the pulmonary artery.

$\uparrow$ Three with left superior vena cava including one with total anomalous pulmonary venous drainage.

passed into the pulmonary artery. As the child was not thriving, thoracotomy was done on March 28, 1960 and a very small ductus arteriosus ligated. A systolic thrill was present over the pulmonary artery and a continuous thrill could be felt over the left lower lobe. Following operation the continuous murmur persisted (Fig. 1A) with a second sound which was split widely. The cardiogram now showed incomplete right bundle-branch block with right axis deviation while the chest radiograph was unchanged. Angiocardiography on October 27, 1960 showed bilateral multiple stenoses of the pulmonary artery (Fig. 1B) and possibly stenosis of the pulmonary valve. The child remains well and no further treatment is contemplated.

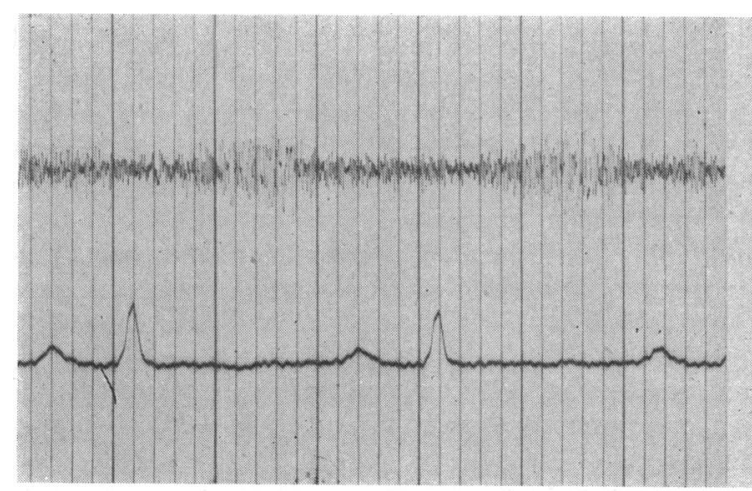

A

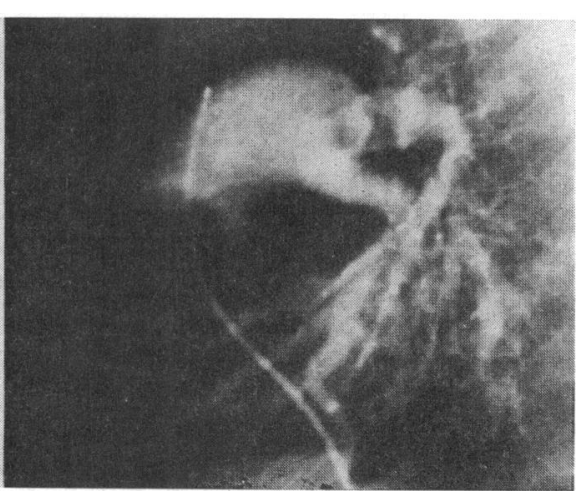

B

FIG. 1.-Patient 1. (A) Phonocardiogram (PCG) recorded over the lower lobe of the left lung, showing continuous murmur waxing towards the end of systole. (B) Angiocardiogram, lateral view, showing bilateral multiple stenoses of the pulmonary artery. 
TABLE

RESUltS OF INVESTIGATIONS

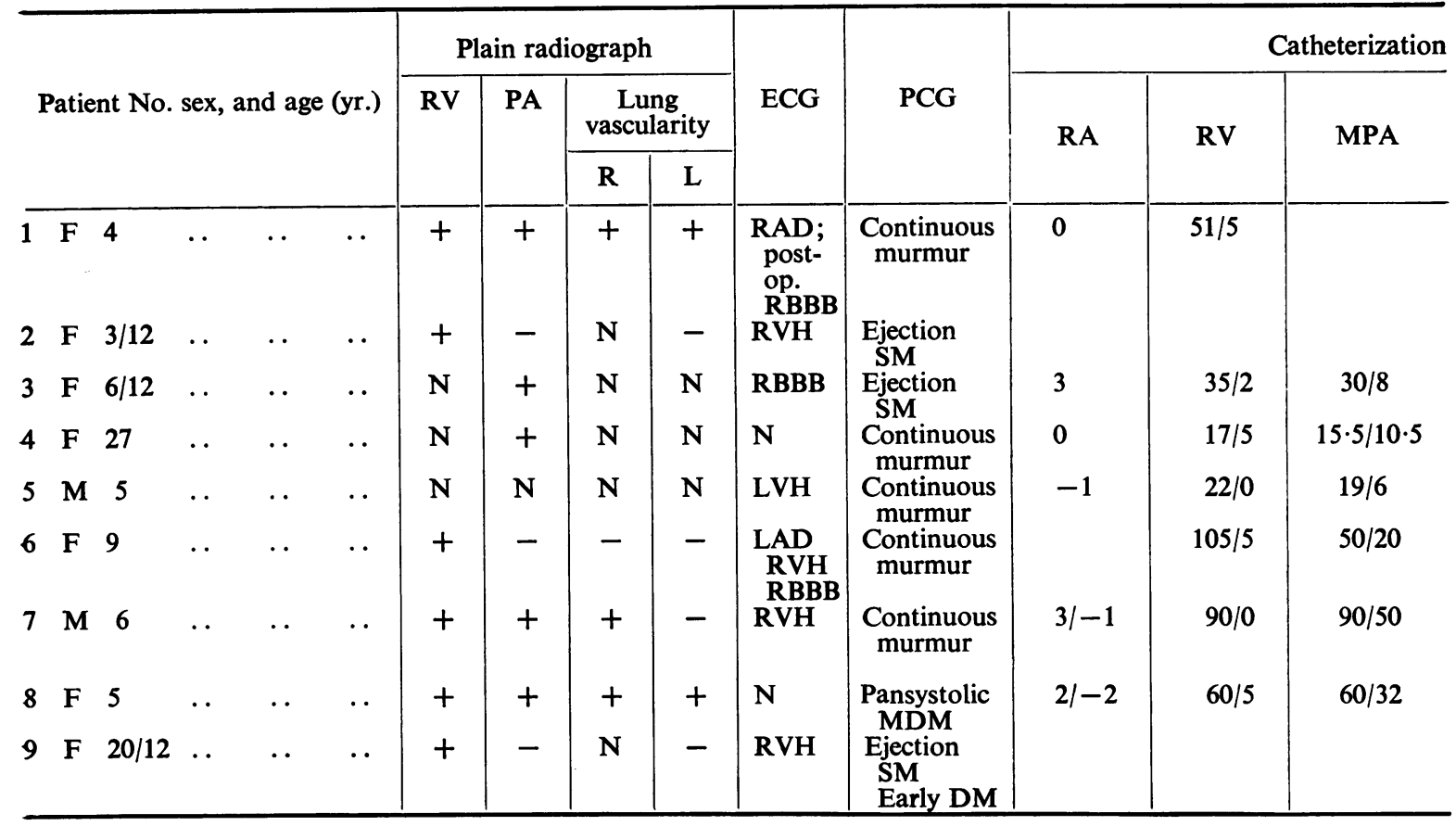

RAD, right axis deviation; RBBB, right bundle-branch block; RVH, right ventricular hypertrophy; I, Type I; diastolic murmur; PF/SF, pulmonary to systemic

Patient 2. A girl, aged 3 months, was referred in September 1959 as a murmur had been heard at an infant welfare clinic. Moderate cyanosis and a pulmonary ejection systolic murmur were observed. At the age of 2 years she was admitted for investigation because of cyanotic attacks. Examination showed an underdeveloped child (height $32 \mathrm{in}$. $(80 \mathrm{~cm}$.); weight, $25 \mathrm{lb}$. $(11.4 \mathrm{~kg}$.)) with central cyanosis and clubbing of the digits. The cardiac impulse was right ventricular in type while the second sound was single. An ejection systolic murmur and thrill were present in the pulmonary area. The cardiogram showed right ventricular hypertrophy with tall $P$ waves in leads II, VR, and VF. Chest radiograph confirmed the right ventricular hypertrophy. The left lung and left main branch of the pulmonary artery were both smaller than those on the right. The peripheral vasculature was diminished but equal in both lungs. Cardiac catheterization was unsuccessful, but angiocardiography demonstrated a high ventricular septal defect and valvular pulmonary stenosis, and showed in addition stenosis of the left main branch of the pulmonary artery and its divisions (Fig. 2). Thoracotomy was done on October 15, 1962, as the child was not thriving. The diagnosis of Fallot's tetrad was confirmed, and $1 \mathrm{~cm}$. from the pericardial reflection the left main branch was narrowed and over this area a systolic thrill was present. A $6 \mathrm{~mm}$. tubular plastic graft was inserted between the aorta and the left pulmonary artery distal to the stenosis. Though the graft was patent, no continuous murmur was heard and cyanosis persisted. One year after operation, the child was more active, was gaining weight, and had had no further cyanotic attacks.

Patient 3. A girl, aged 6 months, was referred in February 1958 as a murmur had been heard during routine examination at an infant welfare clinic. Development was normal and there were no symptoms. At the age of $4 \frac{1}{2}$ years she was admitted for investigation.

Examination showed a child of normal nutrition (height, 40 in. $(100 \mathrm{~cm}$.); weight, $35 \mathrm{lb} .(16 \mathrm{~kg}$.)). An ejection systolic murmur was present at the pulmonary area and the second sound was split, being unaffected by respiration, while the pulmonary component was louder than the aortic (Fig. 3A). The cardiogram showed incomplete right bundle-branch block and right axis deviation, while the chest radiograph was normal except for a prominent pulmonary artery. Cardiac catheterization on August 20, 1962 (Table III) showed 
III

in Our Nine Patients

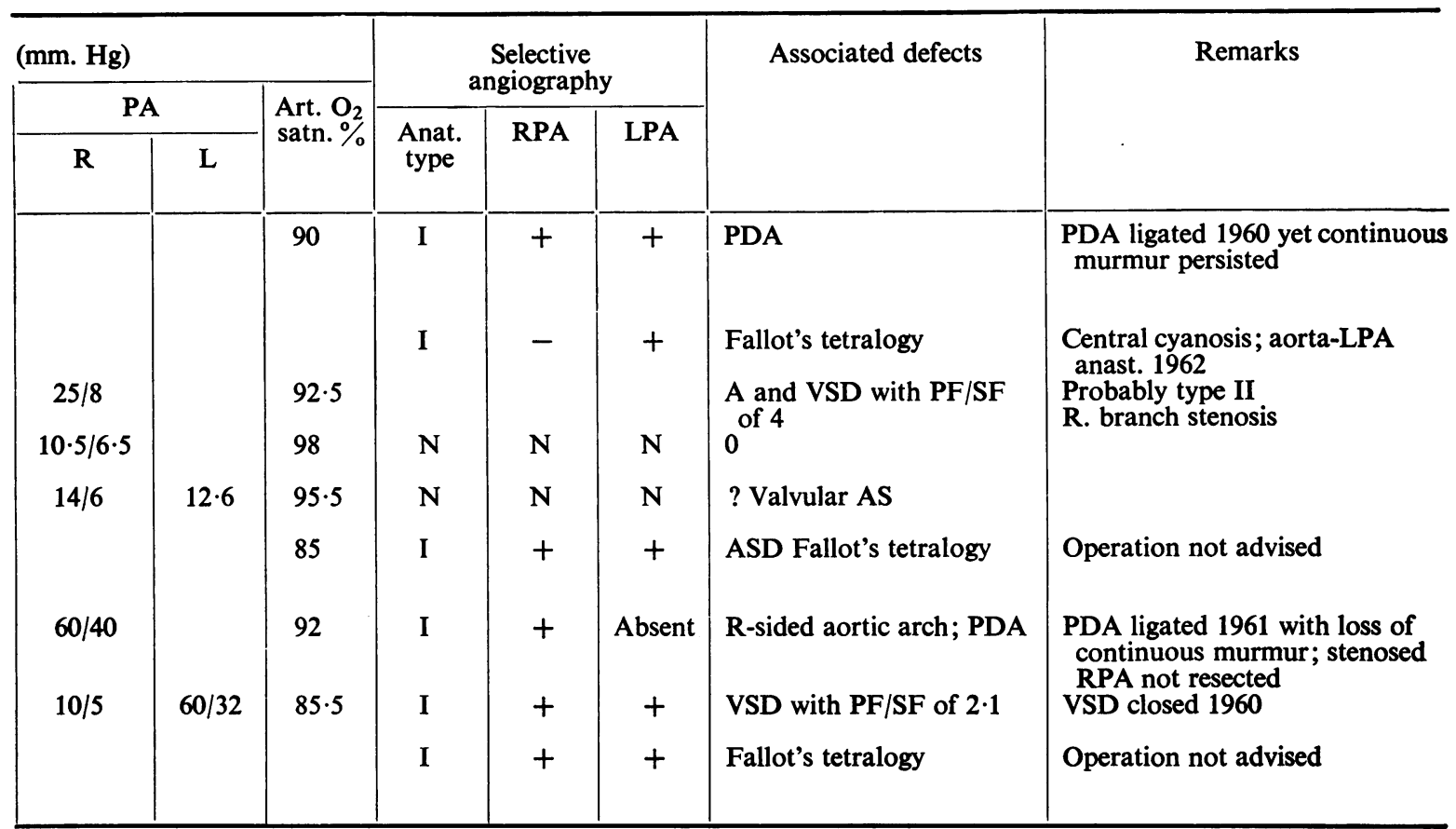

N, normal; LVH, left ventricular hypertrophy; LAD, left axis deviation; SM, systolic murmur; MDM, midflow ratio; PDA, persistent ductus arteriosus.

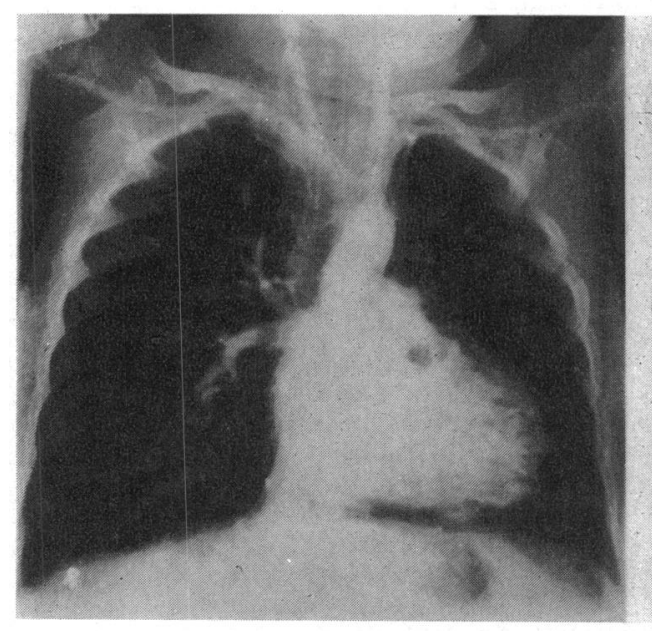

A

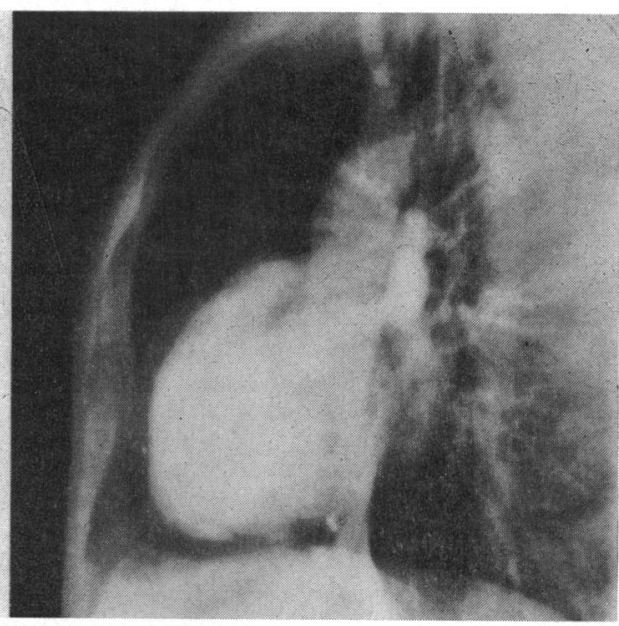

B

Fig. 2.-Patient 2. Angiocardiogram showing simultaneous opacification of the aorta and pulmonary trunk, pulmonary valve stenosis, and almost complete absence of filling of the left main branch of the pulmonary artery. (A) Antero-posterior view. (B) Lateral view. 


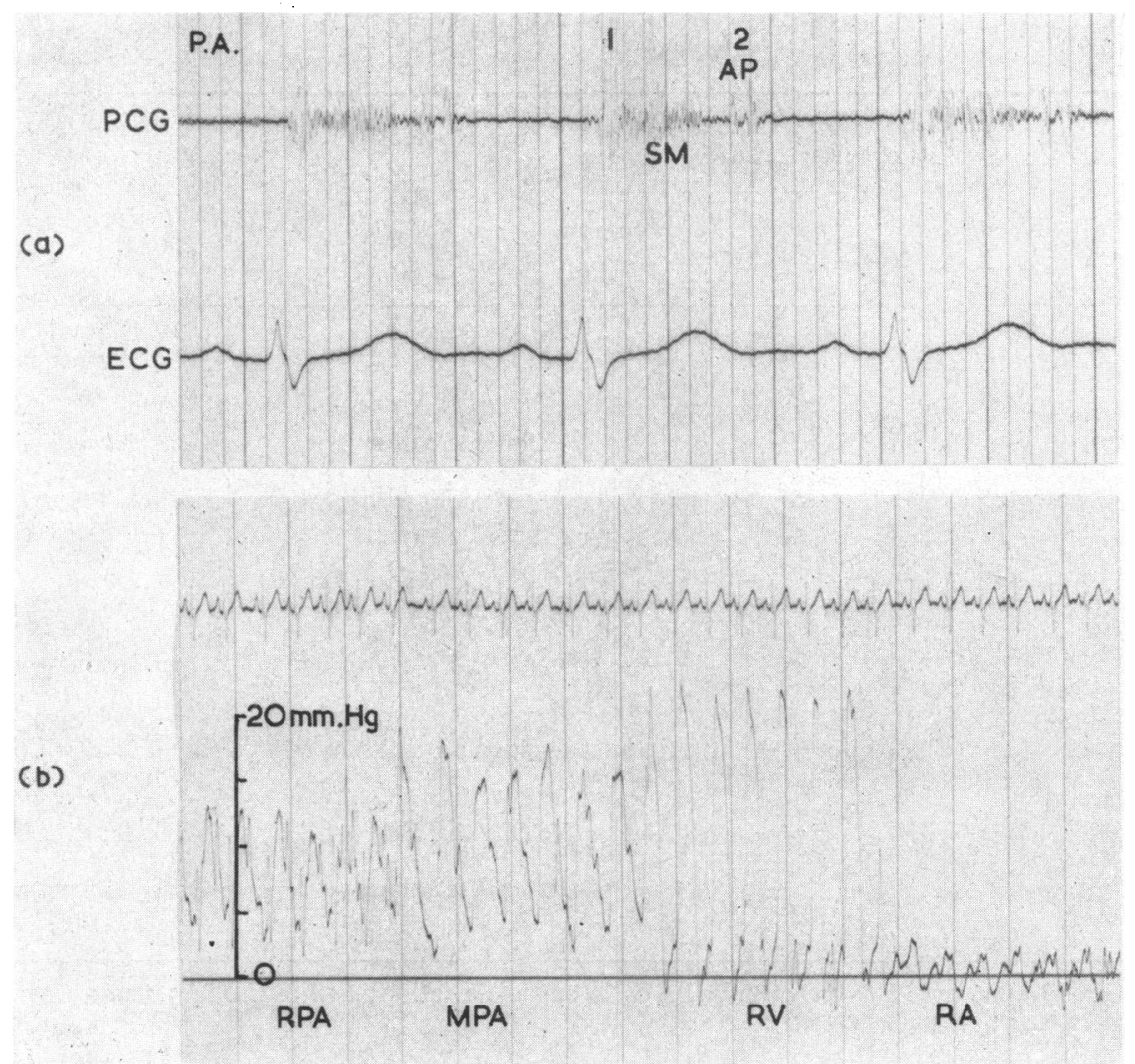

Fig. 3.-Patient 3. (a) Phonocardiogram (PCG) recorded at the pulmonary area showing an ejection systolic murmur (SM) and widely split second sound, the pulmonary component (P) being louder than the aortic (A). Lead II of the electrocardiogram shows incomplete right bundle-branch block. (b) Withdrawal tracing during catheterization showing a systolic gradient of 5-7 mm. from the right main branch (RPA) to the pulmonary trunk (MPA).

both atrial (ostium secundum) and ventricular septal defects with a pulmonary to systemic flow ratio of 4 . The catheter could not be passed into the left main branch of the pulmonary artery, but a tracing taken during withdrawal of the catheter from the right main branch to the pulmonary trunk itself showed a systolic gradient of 5-7 mm. $\mathrm{Hg}$ (Fig. 3B). Angiocardiography was not done. As the child is thriving, operation is not contemplated at present.

Patient 4. A woman aged 27 years was admitted for investigation of a cardiac murmur found during her first pregnancy in 1956. She had no symptoms. A continuous murmur had been heard on occasions in the pulmonary area.

Examination revealed a continuous murmur in the pulmonary area, the blood pressure being $120 / 80$ $\mathrm{mm}$. Hg. No other clinical abnormality was present. An electrocardiogram was normal while a chest radiograph showed a prominent pulmonary artery but was otherwise normal. Cardiac catheterization on April 17, 1959 (Table III) did not demonstrate any septal defect or aorto-pulmonary communication. There was a systolic gradient of $5 \mathrm{~mm}$. $\mathrm{Hg}$ at the origin of the right main branch of the pulmonary artery. No stenosis was demonstrated at angiocardiography, the anatomy being apparently entirely normal.

Patient 5. A boy aged $5 \frac{1}{2}$ was found to have heart disease at the age of $2 \frac{1}{2}$ years and a patent ductus was suspected. Each winter he had had bronchitis and was noted to be cyanosed after exertion.

Examination showed a child of normal nutrition (height, 44 in. $(110 \mathrm{~cm}$.$) ; weight, 35 \mathrm{lb}$. (16 kg.)). A continuous murmur was heard for about two years, but it became more difficult to hear and by the age of 5 only a systolic murmur in the pulmonary area was audible. The blood pressure was $120 / 50 \mathrm{~mm}$. Hg. 


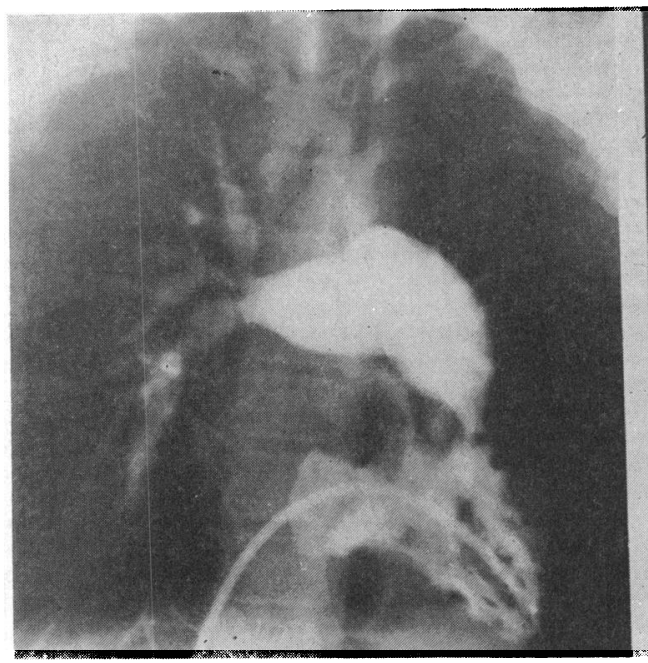

A

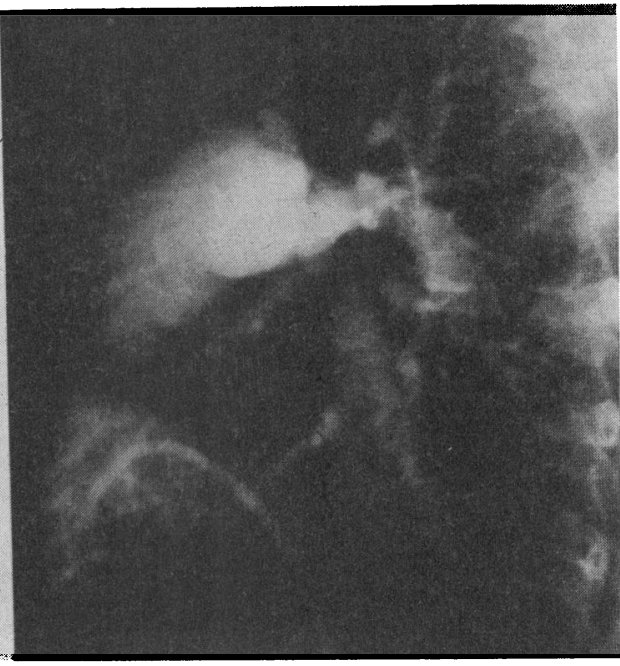

B

FIG. 4.-Patient 6. Angiocardiogram showing infundibular pulmonary stenosis, dilated pulmonary artery with stenoses of the right and left main peripheral branches. (A) Antero-posterior view. (B) Lateral view.

Clinical examination was otherwise normal. An electrocardiogram suggested the possibility of left ventricular enlargement while the chest radiograph was normal. Cardiac catheterization on April 20, 1960 (Table III) showed systolic gradients of 7 and $5 \mathrm{~mm}$. $\mathrm{Hg}$ respectively at the origins of the left and right main branches of the pulmonary artery. No other abnormality was discovered. No stenosis of the right or left main branches was demonstrated at angiocardiography, though one film was suggestive of valvular aortic stenosis.

Patient 6. A girl aged 9 years had had recurrent respiratory infections with attacks of cyanosis for one year. At birth a heart murmur had been observed.

Examination revealed a small child (height, $49 \mathrm{in} .(122 \mathrm{~cm}$.); weight, $63 \mathrm{lb}$. $(29 \mathrm{~kg}$.)) who was cyanosed occasionally at rest. A continuous murmur that had been heard originally in the right infraclavicular region was no longer present, but there was a holo-systolic murmur with a single second sound in the pulmonary area. The cardiogram showed left axis deviation with incomplete right bundle-branch block and right ventricular hypertrophy. The chest radiograph confirmed the right ventricular enlargement while both lungs were oligæmic. The pulmonary arterial branches were small. At cardiac catheterization on June 8, 1949 (Table III) the catheter passed across an atrial septal defect through which there was a right-to-left shunt. Though there was a systolic gradient of $55 \mathrm{~mm}$. $\mathrm{Hg}$ across the pulmonary valve, the pulmonary arterial pressure was $50 / 20 \mathrm{~mm}$. Hg. Angiocardiography on September 11, 1960 showed a short infundibular pulmonary stenosis with a right-to-left shunt across a ventricular septal defect. The pulmonary trunk was dilated, the dilatation extending into the right main branch. At the hilum, the right main branch was narrowed with localized stenoses of all its lobar branches and other peripheral stenoses. In addition the left main branch was narrowed at its origin with several peripheral stenoses (Fig. 4). Operation was not advised.

Patient 7. A boy aged 6 years was found to have heart disease at the age of 6 months. He became dyspnœic on moderate exertion, but never cyanosed.

Examination showed a child (height, $31 \mathrm{in} .(78 \mathrm{~cm}$.); weight, $30 \mathrm{lb} .(13.6 \mathrm{~kg}$.)) with a continuous murmur loudest at the aortic area. In addition a systolic murmur was present posteriorly near the angle of the right scapula. The blood pressure was $100 / 60 \mathrm{~mm}$. Hg. The electrocardiogram showed right ventricular hypertrophy which was confirmed by chest radiograph. The right main branch of the pulmonary artery was dilated while the left lung was oligæmic. At cardiac catheterization on January 24, 1958 (Table III) the catheter traversed a ductus arteriosus. The catheter could not be passed into the left main branch of the pulmonary artery, and there was a systolic gradient of $30 \mathrm{~mm} . \mathrm{Hg}$ at the origin of the right main branch. 


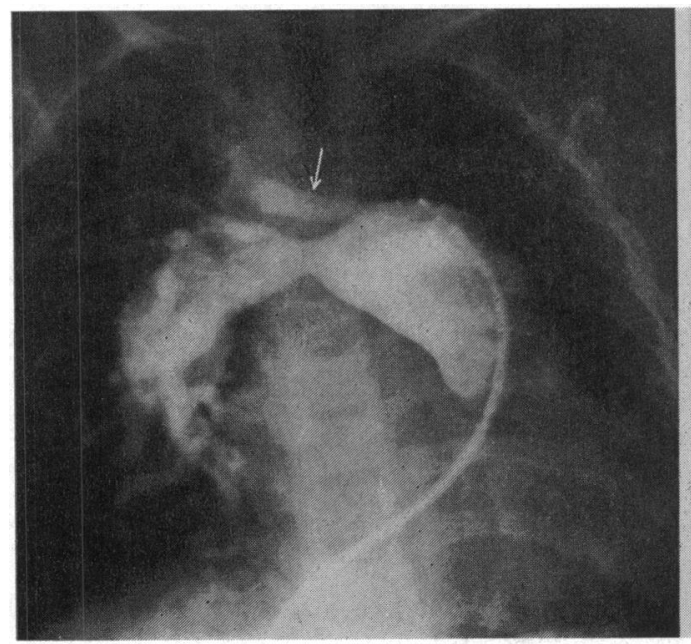

A

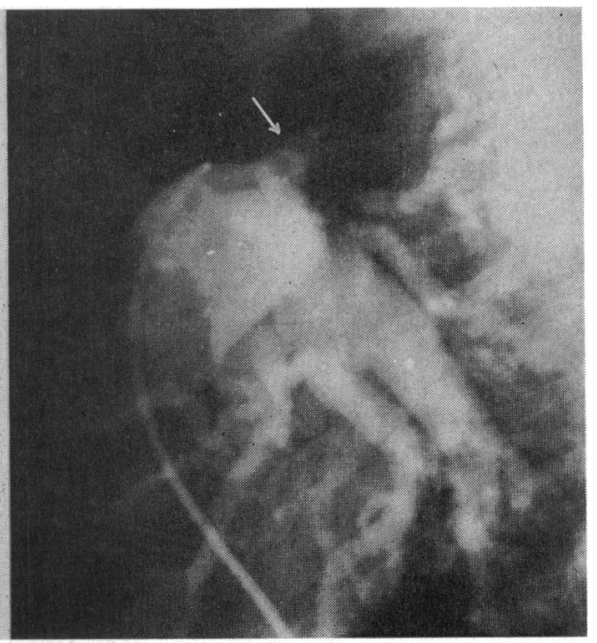

B

FIG. 5.-Patient 7. Angiocardiogram showing huge pulmonary trunk with an absent left main branch and stenosis of the right main branch. A persistent ductus arteriosus crossing to the right-sided aortic arch is marked by the arrows. (A) Antero-posterior view. (B) Lateral view.

Angiocardiography on November 11, 1960 showed a huge pulmonary artery trunk with an absent left main branch. A local stenosis of the right main branch was present just beyond its origin, and distal to this it was dilated, the middle two lobar branches being very large. In addition the right upper lobe artery showed a local stenosis at its origin, with distal dilatation. A ductus arteriosus and a right-sided aortic arch were also present (Fig. 5). Thoracotomy on June 13, 1961 confirmed the absence of the left main branch of the pulmonary artery though the venous drainage of the left lung was normal. A systolic thrill was present over the ductus arteriosus and stenosed right main branch of the pulmonary artery. The ductus was closed but the stenosis of the right main branch of the pulmonary artery could not be resected. After operation the continuous murmur disappeared.

Patient 8. A girl aged 5 had been found to have heart disease at the age of 2 years. She had moderate exertional dyspnoea.

Examination revealed a child of normal development (height, $41.5 \mathrm{in}$. (104 cm.); weight, $35 \mathrm{lb}$. (16 kg.)). No cyanosis or clubbing was present, the blood pressure being $85 / 55 \mathrm{~mm}$. $\mathrm{Hg}$. The right ventricle was enlarged while there was a holo-systolic murmur at the pulmonary area, the second sound being closely split. In addition at the mitral area there was a mid-diastolic murmur. The cardiogram showed the heart to be vertical in position without evidence of right ventricular hypertrophy. Chest radiograph showed an enlarged heart with right ventricular hypertrophy and a prominent pulmonary trunk while the lungs were pleonæmic. Cardiac catheterization in September 1959 (Table III) showed a pulmonary to systemic flow ratio of 2:1 due to a left-to-right shunt across the ventricular septal defect. In addition there was a systolic gradient of $50 \mathrm{~mm}$. Hg at the origin of the right main branch of the pulmonary artery. Angiocardiography on September 23, 1960 confirmed the ventricular septal defect. Both the right and left main branches of the pulmonary artery were small. Multiple peripheral stenoses with fusiform post-stenotic dilatations were also present and were best demonstrated on the lateral film (Fig. 6). In later films a left-to-right shunt was demonstrated across the ventricular septal defect.

On September 30, 1960 the ventricular septal defect was closed using cardio-pulmonary bypass. The pulmonary trunk was large while the right main branch was small. After operation the murmur due to the septal defect disappeared, but a systolic murmur was still heard in the pulmonary area, and the systolic murmur due to the right main branch stenosis was still audible posteriorly. heard.

Patient 9. A girl aged 20 months was seen to have stridor shortly after birth, and a cardiac murmur was

Examination showed a child of normal nutrition (height, $30 \mathrm{in.}(75 \mathrm{~cm}$.); weight, $22 \mathrm{lb} .(10 \mathrm{~kg}$.)) with 


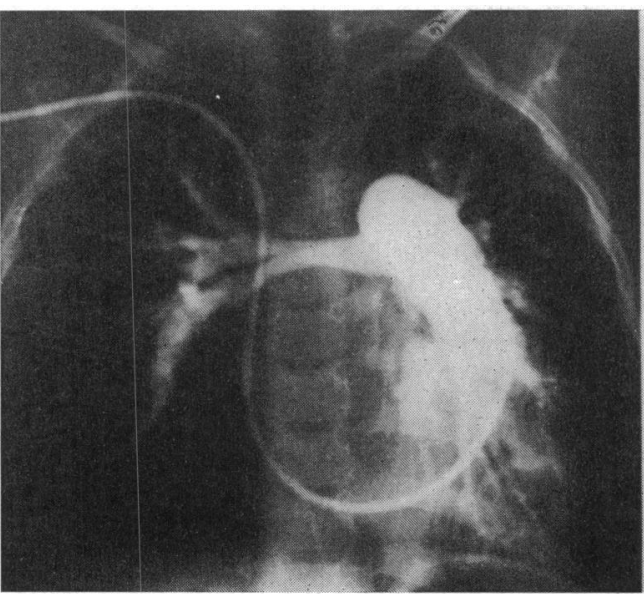

A

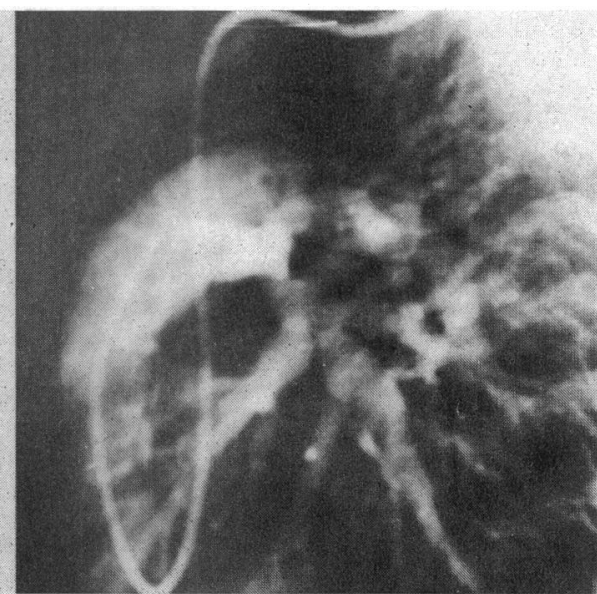

B

FIG. 6.-Patient 8. Angiocardiogram showing a dilated pulmonary artery with stenoses of the right and left main and peripheral branches. (A) Antero-posterior view. (B) Lateral view.

moderate exertional dyspnca and cyanosis but no clubbing. The blood pressure was $100 / 65 \mathrm{~mm}$. $\mathrm{Hg}$. An ejection systolic murmur with a thrill was present at the pulmonary area and an early diastolic murmur was also heard. The electrocardiogram showed right ventricular hypertrophy. The chest radiograph confirmed the right ventricular enlargement. The right main branch of the pulmonary artery and its divisions were normal while the left main branch and its branches were very small. Angiocardiography on December 10, 1963 showed Fallot's tetralogy with infundibular and valvular pulmonary stenosis. The pulmonary trunk was short and narrow, both main branches being small, the left in fact measured only $3 \mathrm{~mm}$. in diameter and supplied a few tiny branches to the lung. Multiple peripheral stenoses were present in the right lung (Fig. 7). Operation was not advised.

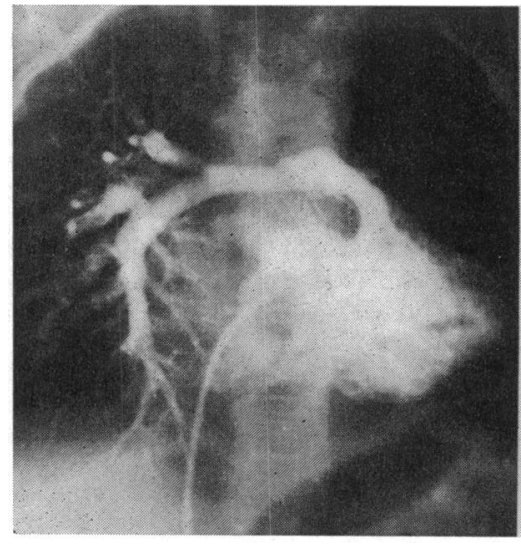

A

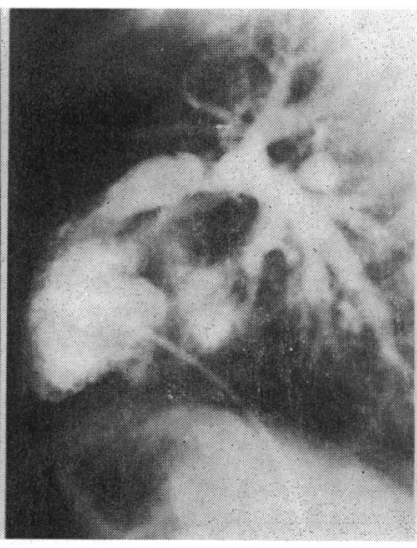

B

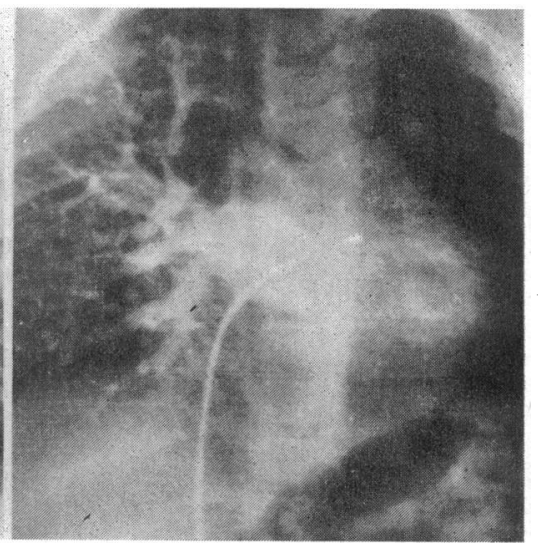

C

FIG. 7.-Patient 9. Angiocardiogram showing a right-to-left shunt through a ventricular septal defect, faint filling of the aorta, and infundibular and pulmonary valvular stenosis. The right main branch of the pulmonary artery is narrow $(7 \mathrm{~mm}$. diam.) with multiple stenoses at the origin of the lobar and segmental arteries and prominent post-stenotic dilatations. The left main branch is tiny $(3 \mathrm{~mm}$. diam.) and rapidly decreases in size with multiple stenoses of its few small branches. The venous phase shows large right pulmonary veins while the left pulmonary veins are invisible. (A) Antero-posterior view. (B) Lateral view. (C) Antero-posterior view showing
venous phase. 


\section{DisCUSSION}

Classification and Atiology. Stenosis of the pulmonary artery and its branches is usually congenital but it can be acquired. The obstruction may be single, usually affecting the main trunk of the artery, or multiple in which case it may be unilateral or bilateral. At times the stenosis may affect both the main pulmonary trunk and the peripheral branches (Table I). Of the 117 patients, 49 were examples of Type I, 49 of Type II, 11 of Type III, and 8 of Type IV (Table II). Type IV consisted of 3 patients with combined Type I and II deformities, 2 with Types I and III, and 3 with Types II and III. An extreme example of the condition is atresia of the pulmonary artery which may consist of cord-like segments of varying length. The atresia may or may not be associated with stenosis of the pulmonary valve. Rarely the left main branch of the pulmonary artery may be absent.

That the lesion is congenital is suggested by its occurrence following maternal rubella (Gyllenswärd et al., 1957; Arvidsson et al., 1961 ; Liggins and Phillips, 1963); its association with other congenital anomalies, both cardiac defects especially Fallot's tetralogy, pulmonary valvular stenosis, and atrial or ventricular septal defects, and non-cardiac defects such as cataract, cleft palate, deaf mutism, and hypertelorism; and its age distribution, over two-thirds occurring in the first decade. Further support is given by the familial occurrence of the disorder: thus, the sixth patient described by Gyllenswärd et al. (1957) was the son of the woman previously reported by Arvidsson, Karnell, and Möller (1955); and the two patients reported by Van Epps (1957) were brothers.

Søndergaard (1954) has suggested that stenosis of the pulmonary artery at its bifurcation results from closure of the ductus arteriosus, just as Craigie (1841), supported later by Skoda (1855), had supposed this might account for the origin of the adult type of coarctation of the aorta. For this reason Søndergaard referred to stenosis at this site as "coarctation of the pulmonary artery". However, the Skodaic theory of the origin of coarctation of the aorta has been attacked convincingly by Edwards et al. (1948). Though the bifurcation of the pulmonary artery is a common site for stenosis, particularly when Fallot's tetralogy is present, the theory would not account for the presence of stenosis situated more peripherally or of the common multiple ones.

Acquired stenosis of the pulmonary artery and its branches is rare. One of us (J.N.P.) has seen it on three occasions result from pressure of a tumour while Waldhausen, Lombardo, and Morrow (1959) have reported a similar example. Moller (1922) has demonstrated multiple partially absorbed pulmonary emboli or thrombi that could easily give rise to the curious rounded or scalloped obstructions shown so clearly in the angiocardiograms of the first patient of the series described by Arvidsson et al. (1955). Dimond and Jones (1954) have reported an example of multiple stenoses of the left main branch following pulmonary arterial thrombosis of traumatic origin.

Morbid Anatomy. When the lesion is isolated, opportunity for necropsy is rare owing to its benign clinical nature. Even at necropsy it may not always be possible to determine whether the cause of the obstruction is congenital or acquired.

At times the stenosis may be due to a diaphragm or membranous septum-like constriction (Gyllenswärd et al., 1957; Kjellberg et al., 1959), or it may be elongated for a few millimetres or even a centimetre or two. Sometimes medial sclerosis and calcification may be widespread in the region of the obstruction (Oppenheimer, 1938), and may form a calcific ring necessitating surgical dilatation (Shumacker and Lurie, 1953). The obstruction may admit only a probe, and if it is complete then atresia is a more appropriate term.

There is often dilatation of the pulmonary arterial branch beyond the stenosis, and this is almost invariable if the stenoses are multiple. It is presumably due to hæmodynamic forces acting on the vessel wall as in other post-stenotic dilatations (Holman, 1954). Rarely, blind-ending vascular sacs arise from the pulmonary artery and are thought to be the central remains of vascular primordia running in an abnormal direction (Gyllenswärd et al., 1957).

Sometimes the pulmonary arterial tree may be hypoplastic, either both main branches (Arvidsson et al., 1955) or only one branch, as in the first patient reported by Gyllenswärd et al. (1957) and the second and ninth patients of our series. The main pulmonary trunk may be dilated yet the peri- 
pheral branches show multiple constrictions, as in the fifth patient described by Gyllenswärd and his colleagues (1957) and the seventh patient of our series.

At times the pulmonary vascular bed may be reduced considerably by obliteration or aplasia of the lower lobe arteries, as in the second patient described by Arvidsson et al. (1955). In this patient the lower portions of the lungs received their blood supply from the bronchial arteries. This was demonstrated by angiocardiography which showed simultaneous opacification of the bronchial arteries and aorta.

Occasionally the left main branch of the pulmonary artery is entirely absent and the right may show single or multiple stenoses (Gunning, 1957; Loehr, Loogen, and Vieten, 1961). We have encountered one such example (Patient 7, Fig. 5). We can find no record of the right main branch being absent.

The principal histological changes include fibrous proliferation of the intima at the stenosis, and distal to the obstruction the artery is thin walled and dilated with variable loss of elastic tissue in the media, with or without intimal proliferation (Gay et al., 1963). Such a pattern resembles that found in fibromuscular stenosis of the renal arteries.

Saphir (1932) has reported two examples in which histological examination showed that the anomaly was due to organized mural thrombi. The first showed bands measuring 3-10 $\mathrm{mm}$. affecting both the right and left main branches of the pulmonary artery but not the trunk, and the second had distinct ridges in some of the branches of the main pulmonary artery. From Saphir's illustrations of the specimens it seems that though the stenosis of the pulmonary artery and its branches might not cause any sudden alteration of pressure, the passage of a catheter might well become obstructed. In a patient of Dimond and Jones (1954), where necropsy revealed the entire right main branch of the pulmonary artery to be occluded by thrombus, the left main branch also contained thrombus, canalized in such a manner that the angiocardiogram could easily simulate multiple stenoses. The patient's chest had been severely bruised in a car accident five months previously. He had been in excellent health before the accident, which was thought to have caused in situ thromboses of the pulmonary artery.

The obstructions, whether single or multiple, can at times be sufficiently severe to give rise to right ventricular hypertrophy, and such pressure transmitted to the right atrium may result in a rightto-left shunt through a patent foramen ovale (Dimond and Jones, 1954).

Clinical Features. The age range when the patients were first seen was from a few months to 33 years. Eighty-one were 9 years old or less, and the sex ratio was approximately unity (Table II).

The patient with post-valvular pulmonary arterial stenosis may fail to thrive. Thus, where a note was made of the physical state, one-half were poorly developed and this did not seem always to be associated with cyanosis. In the absence of other lesions, cyanosis is uncommon but may appear on exertion if the stenosis is severe when right ventricular hypertension may cause a right-toleft shunt through a patent foramen ovale.

Dyspnœa was not a prominent symptom in the absence of associated defects. Hæmoptysis is rare, but Van Epps (1957) has described it resulting from large post-stenotic pulmonary arterial aneurysms.

The auscultatory signs will obviously depend on whether an associated cardiac lesion is also present, as was the case in 72 of 117 patients, and these signs often obscure and modify those due to stenosis of the pulmonary artery. In severe stenosis of the pulmonary valve the second sound is single, being due to aortic valve closure. In contrast, in post-valvular pulmonary arterial stenosis, and as would be expected when central pulmonary hypertension is present, the second sound is frequently split, the pulmonary component being loud. However, if stenosis is both valvular and post-valvular, as in two of our patients, then the second sound may be single. Kjellberg et al. (1959) have published a phonocardiogram from a patient with membranous pulmonary artery stenosis in which an extra sound was recorded after the second sound, presumably caused by the membrane which was about $1.5 \mathrm{~cm}$. above the pulmonary valve.

A systolic murmur was absent in only 6 of 36 isolated and 2 of 62 combined examples of the dis- 
order. It is usually of ejection type but may be pansystolic and is best heard along the left sternal edge.

The diastolic murmur usually begins with the second sound and may be short, so that it is then incorrect to speak of a continuous murmur. For this murmur Franch and Gay (1963) have used the term quasi-continuous. When genuinely continuous, the murmur may be mistaken as evidence of a persistent ductus arteriosus, the resemblance being so close that patients have been explored (Eldridge, Selzer, and Hultgren, 1957). One of our patients (Patient 1) had both a small persistent ductus and pulmonary arterial stenosis, and it was only when the continuous murmur persisted after the ductus had been ligated that the correct diagnosis became obvious. All patients show a systolic pressure gradient and some have in addition a diastolic gradient. It is likely that the diastolic gradient results in the systolic murmur being continued into diastole. From study of the examples published, it seems that the pulmonary arterial stenosis must be severe to produce a continuous murmur. Recently, Eldridge and his colleagues (1957) have shown that constriction of a large branch of the pulmonary artery results in a systolic murmur, but with increasing flow through the constriction a continuous murmur is produced. Thus in order to have a flow in diastole of sufficient volume and velocity to produce turbulence great enough to give rise to a murmur, a reservoir of blood under pressure must exist proximal to the constriction. A gradient must be present not only in systole but throughout the entire cycle. To us, the systolic ballooning of the pulmonary arteries proximal to the stenosis, with subsequent emptying during a varying part of diastole, resembles closely the mechanism of the bagpipe. Of the 117 patients, murmurs were commented on in 98 . A continuous murmur was present in 23 of these; 6 in the 36 isolated examples and 17 in the 62 combined, a patent ductus arteriosus being present in 11 of the latter. Of our 9 patients, 5 had a continuous murmur, of whom 2 had a persistent ductus arteriosus, and 1 had Fallot's tetrad complicated by an atrial septal defect. One had both systolic and early diastolic murmurs.

The association with other congenital cardiac defects is important. Thus 72 of 117 patients had such abnormalities, of whom 24 had multiple defects and 17 the tetrad of Fallot. 31 had only a single additional anomaly, pulmonary stenosis and ventricular septal defect being equally common (Table II). Of particular interest is the occurrence of a left superior vena cava in three subjects including one with total anomalous pulmonary venous drainage, since not only may this lesion be associated with Fallot's tetralogy (Campbell and Deuchar, 1954) but it can also give rise to a continuous murmur (Keith et al., 1954).

Taybi et al. (1963) have described some form of peripheral pulmonary arterial stenosis in 10 of 13 patients with supravalvular aortic stenosis. The defect appeared to be transmitted by an autosomal dominant gene. In a review of the published reports they found only 3 such examples among 54 patients with supravalvular aortic stenosis. Recently Williamson (1964) has reported one further example. Among these 117 cases of pulmonary arterial stenosis we have found 4 with aortic stenosis (Table II), and in 2 of them the obstruction was supravalvular.

Special Investigations. Electrocardiogram. Although the electrocardiogram may be normal, it usually reflects right ventricular hypertrophy if the stenosis is severe, even in the absence of any other congenital cardiac lesion. Of 27 patients with isolated pulmonary arterial stenosis the cardiogram was normal in 7, right ventricular hypertrophy being present in 20 . Of 58 patients with combined defects, the electrocardiogram was normal in only 3 , right ventricular hypertrophy being present in 45, left ventricular hypertrophy in 7, and biventricular hypertrophy in 3 .

Radiology. The chest radiograph is usually normal though when right ventricular hypertrophy is present it may be evident in the radiograph as well as in the electrocardiogram. More important is the state of the pulmonary artery and its branches. Thus with valvular stenosis there may be post-stenotic dilatation of the main pulmonary trunk while this is absent in isolated pulmonary arterial stenosis. Similarly, with an associated atrial or ventricular septal defect and left-to-right shunt, there may be dilatation of the main pulmonary trunk and its branches radiologically. In contrast, with bilateral peripheral stenoses of the branches of the pulmonary artery the lung fields may be oligæmic. At times, the small vascular dilatations can be made out. If the obstruction is 
unilateral the contrast between the two lung fields may be obvious. In some patients the plain chest radiograph may show a typical change in the hilar region, the central branches of the pulmonary artery being poorly marked and narrow when compared with the post-stenotic dilatations of the more peripheral parts. It is even possible in some cases to make the diagnosis from such films (Gyllenswärd et al., 1957). Fluoroscopy may reveal excessive pulsation in the post-stenotic dilated branches of the pulmonary artery distal to the hilar region, especially if image intensification is employed (Gay and Franch, 1960).

The first angiocardiographic report of the lesion appears to be that of Powell and Hiller (1955). Final diagnosis must rest on the demonstration of the stenosis or stenoses by selective angiocardiography of the pulmonary arterial tree, which will show not only the sites of obstruction but also the post-stenotic dilatations. If the obstruction is membranous it may be rendered invisible by the overlapping of the post-stenotic dilatations, and unless two-plane angiograms are taken the stricture may be missed.

Cardiac catheterization may reveal the diagnosis by demonstrating one or more pressure gradients in the branches of the pulmonary artery (Fig. 3). Williams, Lange, and Hecht (1957) have shown that considerable obstruction must exist in the pulmonary artery to produce a measurable gradient, for example a 50 per cent reduction in diameter will result in only a $9 \mathrm{~mm}$. $\mathrm{Hg}$ mean gradient. Conversely with an increased pulmonary flow consequent on a septal defect, a high gradient may result even though the obstruction be slight. In addition, valvular stenosis may mask stenosis or stenoses of the branches of the pulmonary artery. Fallacious obstruction may be diagnosed by failing to disengage completely the catheter from the "wedged" position. Careful observation of the catheter by fluoroscopy, and estimation of the oxygen saturation of blood samples, will confirm the site of the obstruction. According to Franch and Gay (1963) increased pulmonary flow alone may be responsible for a pressure differential between the pulmonary trunk and its right main branch at their sharply angulated junction. Ideally, selective angiocardiography should be available, and if a pressure gradient is found a small quantity of contrast medium should be injected just proximal to the obstruction. However, in two of our patients catheterization suggested peripheral stenoses but subsequent angiocardiography failed to confirm this. Recently, Weinberg et al. (1964) have published a similar example (their Case 4).

Agustsson et al. (1962) have reported a characteristic pressure curve in patients with bilateral stenoses of the pulmonary artery branches. They found that the descending limb of the curve was steeper, with a deeper dicrotic notch and a lower diastolic plateau than in normal subjects. These changes were related to the severity of the obstruction, and this may be the reason why we did not find them in our patients. Such pressure tracings were unaffected by an associated left-to-right shunt or stenosis of the pulmonary valve, and are found also in supra-valvular aortic stenosis (Gupta and Wiggers, 1951; Denie and Verheugt, 1958; Morrow et al., 1959). Dean et al. (1962) in a series of 20 patients also noted the low diastolic pressure but recorded that the ascending limb of the systolic pulse was less steep. It was suggested by Agustsson and his colleagues (1962) that, in postvalvular pulmonary stenosis, the pulmonary artery proximal to the obstruction functioned as an outlet chamber continuous with the right ventricle in systole. In diastole, the stenotic area constricts and the pulmonary valve cusps bulge into the right ventricular outflow tract. Presumably this would explain the early diastolic murmur found in severe post-valvular pulmonary stenosis. Another pitfall in diagnosis by catheterization is that, occasionally, records taken from the pulmonary artery near the orifice of a persistent ductus may show a higher pressure than more distal ones (Levinson et al., 1951).

Of 104 patients where the results of cardiac catheterization were known, the right ventricular and pulmonary arterial pressures were normal in only 4 . In the remaining 100 both the right ventricular and pulmonary arterial pressures were raised in 76 and the right ventricular pressure was alone raised in 24. The relation to the presence or absence of a shunt can be seen from Table IV.

Differential Diagnosis. Post-valvular pulmonary stenosis may masquerade clinically as valvular 
TABLE IV

Relation of Right Ventricular and Pulmonary Arterial Pressures to Absence, Presence, and Direction of SHUNT

\begin{tabular}{|c|c|c|c|c|c|c|}
\hline \multicolumn{3}{|l|}{ Pressures } & \multirow[t]{2}{*}{ Shunt absent } & \multicolumn{2}{|c|}{ Shunt present } & \multirow[t]{2}{*}{ Total } \\
\hline & & & & L. to $\mathbf{R}$. & R. to $\mathrm{L}$. & \\
\hline $\begin{array}{l}\text { R.V. and P.A. raised } \\
\text { R.V. only raised.. } \\
\text { R.V. and P.A. normal }\end{array}$ & $\begin{array}{l}\ldots \\
\ldots\end{array}$ & $\begin{array}{l}\ldots \\
\cdots\end{array}$ & $\begin{array}{r}45 \\
13 \\
4\end{array}$ & $\begin{array}{r}26 \\
3\end{array}$ & $\begin{array}{l}5 \\
8\end{array}$ & $\begin{array}{r}76 \\
24 \\
4\end{array}$ \\
\hline Total $\quad$. & . & .. & 62 & 29 & 13 & 104 \\
\hline
\end{tabular}

pulmonary or aortic stenosis, atrial septal defect, or persistent ductus arteriosus (Dean et al., 1962), while on the other hand such defects may mask its presence (Bell et al., 1962).

In any patient with stenosis of the pulmonary valve, accompanied by an early diastolic murmur, post-valvular arterial stenosis should be suspected. When a continuous murmur is present in severe post-valvular pulmonary stenosis it may be confused with a persistent ductus arteriosus. Furthermore, if the pulmonary arterial stenosis is overlooked, operative treatment of such disorders as Fallot's tetralogy may be more hazardous.

It must be admitted that a continuous murmur, confirmed phonocardiographically, may exist without satisfactory explanation. We have encountered two such examples. In one, a woman of 67 , angiocardiography revealed a rather large pulmonary trunk $(25 \times 35 \mathrm{~mm}$.), the right main branch of the pulmonary artery being $22 \mathrm{~mm}$. at its origin and dilated slightly towards the hilum, and the left main branch $28 \mathrm{~mm}$. at its origin. There was no evidence of stenosis. In the other patient, a man of 33 , there was only a very small systolic gradient $(2.5 \mathrm{~mm}$. Hg) in the right main branch of the pulmonary artery, and angiocardiography did not reveal any evidence of stenosis.

Prognosis. The outlook must depend on the severity of the lesion and other associated abnormalities, and it is often the nature of the latter that determines the outcome. The finding may be a coincidental one, of little or no significance hæmodynamically, and require no treatment. On the other hand, obstruction may result in failure to thrive, cause central cyanosis on exertion, later, permanent reversal of the shunt across a foramen ovale. Only one patient has been described in the fourth decade of life, though it is of course possible that some examples of isolated pulmonary arterial stenosis may have no impressive murmur and no disability.

Deterioration can certainly take place within a year or two. The only patient we can find where this has been measured is a girl of 13 years, with isolated multiple pulmonary arterial stenosis, reported by Gyllenswärd et al. (1957). Observed over a two-year period, her pulmonary arterial and right ventricular pressures rose from $56 / 18$ and $60 / 0$ to $78 / 31$ and $78 / 0 \mathrm{~mm}$. $\mathrm{Hg}$ respectively, and her chest radiograph showed an increase in heart size. Other patients with severe pulmonary arterial stenosis, however, do not seem to worsen over many years (Friesinger, Criley, and Ross, 1962).

Treatment. In the majority of patients the lesion is benign and no treatment is indicated. The indications for operation would be the development of severe pulmonary hypertension in the absence of any other cause, and possibly severe hæmoptysis. Proximal post-valvular stenosis, especially if membranous, should prove amenable to surgical relief, but not distal and multiple stenoses. Though the lesion rarely lends itself to correction by operation, Shumacker and Lurie (1953) have reported successful dilatation of a calcified constriction $2 \mathrm{~cm}$. distal to the origin of the main pulmonary trunk by means of a Kelly clamp. Improvement included considerable relief of cyanosis. Segmental narrowing of the main pulmonary trunk has been successfully dilated by means of a uterine sound (Williams et al., 1957), and occasionally the narrowed pulmonary artery can be adequately widened by longitudinal incision and transverse closure (Thrower, Abelmann, and Harken, 
1960). Sauvage, Rudolph, and Gross (1960) have replaced the bifurcation of the pulmonary trunk by autogenous pericardium, and Baxter, Booth, and Sirak (1961) have overcome stenosis involving the proximal part of the right main branch of the pulmonary artery by inserting a plastic graft between the distal part of it and the main pulmonary artery. In our second patient the obstructions at the pulmonary valve and in the left main branch of the pulmonary artery were bypassed by a tubular plastic graft inserted between the aorta and the left main branch distal to the obstruction.

If the source of a severe hæmoptysis can be localized, or bleeding is associated with the rapid development of a pulmonary artery aneurysm, then removal of the lung segment or lobe should be considered.

Should operation not prove feasible, it would seem reasonable in patients without severe hæmoptysis to maintain anticoagulant therapy indefinitely, particularly in those patients where thrombotic obliteration is suspected. There is abundant clinical and experimental evidence to show that even total occlusion of one main branch of the pulmonary artery does not cause pulmonary hypertension provided the flow is not increased and the pulmonary vascular bed is normal. Consequently one must be sure that the stenoses are the cause of the pulmonary hypertension and that no other congenital anomaly is responsible.

\section{CONCLUSIONS}

In the less severe cases, without measurable effect hæmodynamically, it is doubtful if the diagnosis can be suspected on clinical grounds alone. If in these patients the diagnosis is suspected at cardiac catheterization, because of a gradient in the pulmonary trunk or its branches distal to the pulmonary valve, it should be confirmed by selective angiocardiography. Similarly, in patients who also have associated congenital cardiac defects, the condition is nearly always masked by them. An early diastolic murmur or a continuous murmur in association with pulmonary valvular stenosis, however, should be a strong hint to seek carefully at catheterization for gradients distal to the stenosed pulmonary valve. In addition, when a continuous murmur is present in severe Fallot's tetralogy, pulmonary arterial stenosis should be excluded before it is assumed that the murmur is due to flow through collateral vessels.

In the more severely affected patients with isolated stenosis of the pulmonary artery, a clinical picture emerges that should, we think, prove sufficiently characteristic to enable diagnosis at the bedside. The child is likely to be underdeveloped, and cyanosis may be present either at rest or only on exercise. A left-sided parasternal heave due to a large right ventricle may be present, and a closely split second sound with accentuation of the pulmonary element due to central pulmonary hypertension will be found. A systolic, systolo-diastolic or continuous murmur may be heard, perhaps best at some distance from the pulmonary area. Right ventricular enlargement is more likely to be found electrocardiographically than radiologically. Though confirmatory angiocardiography is usually required and a plain radiograph of the chest is commonly normal, at times vascular dilatations are discernible, and a plain radiograph may also reveal a characteristic appearance of diminished pulmonary arterial branch shadows at the hilum with heavier shadows a little further out. Absence of a pulmonary trunk may be obvious too. Fluoroscopy may reveal intrinsic pulsations peripheral to the hilar vessels.

If, during cardiac catheterization, it were routine procedure for a complete withdrawal tracing to be recorded slowly from the "wedge" position to the right ventricle, fewer examples of the syndrome would be missed.

\section{SUMMARY}

The published reports on post-valvular stenosis of the pulmonary artery and branches are reviewed and 9 further examples are added. The clinical features derived from an analysis of 117 patients are described. The importance of cardiac catheterization and angiocardiography is stressed.

We wish to thank Dr. Evan Bedford, Mr. W. P. Cleland, Dr. Walter Somerville, and Dr. M. J. Wilmers for permission to include their patients in this series. We are also grateful for the assistance given by our technicians in the Cardiac Department, King's College Hospital, and the Radiodiagnostic Department, Middlesex Hospital. 


\section{REFERENCES}

Agustsson, M. H., Arcilla, R. A., Gasul, B. M., Bicoff, J. P., Nassif, S. I., and Lendrum, B. L. (1962). The diagnosis of bilateral stenosis of the primary pulmonary artery branches based on characteristic pulmonary trunk pressure curves. A hemodynamic and angiocardiographic study. Circulation, 26, 421.

Arvidsson, H., Karnell, J., and Möller, T. (1955). Multiple stenosis of the pulmonary arteries associated with pulmonary hypertension, diagnosed by selective angiocardiography. Acta. radiol. (Stockh.), 44, 209.

- Carlsson, E., Hartmann, A., Jr., Tsifutis, A., and Crawford, C. (1961). Supravalvular stenoses of the pulmonary arteries. Report of eleven cases. Acta. radiol. (Stockh.), 56, 466.

Baxter, C. F., Booth, R. W., and Sirak, H. D. (1961). Surgical correction of congenital stenosis of the right pulmonary artery accompanied by agenesis of the left pulmonary artery. J. thorac. cardiovasc. Surg., $41,796$.

Bell, A. L. L., Jr., Kightlinger, B., Shimomura, S., and Krstulovic, V. (1962). Postvalvular pulmonary artery stenosis: hæmodynamic and radiographic definition. Circulation, 26, 685.

Campbell, M., and Deuchar, D. C. (1954). The left-sided superior vena cava. Brit. Heart J., $16,423$.

Coles, J. E., and Walker, W. J. (1956). Coarctation of the pulmonary artery. Amer. Heart J., 52, 469.

Craigie, D. (1841). Instance of obliteration of the aorta beyond the arch, illustrated by similar cases and observations. Edinb. med. surg. J., 56, 427.

Dean, D. C., Vlad, P., Lambert, E. C., Bunnell, I. L., and Greene, D. G. (1962). Physiologic studies in patients with multiple supravalvular pulmonary artery stenoses. Circulation, 26, 706.

Denie, J. J., and Verheugt, A. P. (1958). Supravalvular aortic stenosis. Circulation, 18, 902.

Dimond, E. G., and Jones, T. R. (1954). Pulmonary artery thrombosis simulating pulmonic valve stenosis with patent foramen ovale. Amer. Heart J., 47, 105.

Edwards, J. E., Christensen, N. A., Clagett, O. T., and McDonald, J. R. (1948). Pathologic considerations in coarctation of the aorta. Proc. Mayo Clin., 23, 324.

Eldridge, F., Selzer, A., and Hultgren, H. (1957). Stenosis of a branch of the pulmonary artery. An additional cause of continuous murmurs over the chest. Circulation, 15, 865.

Franch, R. H., and Gay, B. B., Jr. (1963). Congenital stenosis of the pulmonary artery branches. Amer. J. Med., 35,512 .

Friesinger, G. C., Criley, J. M., and Ross, R. S. (1962). Diagnostic problems in cyanotic heart disease in the adult. Proc. 43rd Ann. Sess., Amer. Coll. Phys. Lancaster, Pa.

Fürst, L. (1878). In Handbuch der Kinderkrankheiten, ed. C. Gerhardt, p. 583, vol. 3, pt. 2. Laupp, Tübingen.

Gay, B. B., Jr., and Franch, R. H. (1960). Pulsations in pulmonary arteries as observed with roentgenoscopic image amplification: observations in patients with isolated valvular stenosis. Amer. J. Roentgenol., 83, 335.

-, Shuford, W. H., and Rogers, J. V. (1963). The roentgenolic features of single and multiple coarctations of the pulmonary artery and branches. Amer. J. Roentgenol., 90, 599.

Gunning, A. J. (1957). An unusual cause of a continuous murmur simulating persistent ductus arteriosus and associated with other congenital cardiac defects. Thorax, $12,34$.

Gupta, T. C., and Wiggers, C. J. (1951). Basic hemodynamic changes produced by aortic coarctation of different degrees. Circulation, 3, 17.

Gyllenswärd, A., Lodin, H., Lundberg, A., and Möller, T. (1957). Congenital multiple peripheral stenoses of the pulmonary artery. Paediatrics, 19, 399.

Holman, E. (1954). The obscure physiology of poststenotic dilatation: Its relation to the development of aneurysms. J. thorac. Surg., 28, 109.

Keith, J. D., Rowe, R. D., Vlad, P., and O'Hanley, J. H. (1954). Complete anomalous pulmonary venous drainage. Amer. J. Med., 16, 23.

Kjellberg, S. R., Mannheimer, E., Rudhe, U., and Jonsson, B. (1959). Diagnosis of Congenital Heart Disease, 2 nd. ed., p. 149. Year Book Publishers, Chicago.

Levinson, D. C., Cosby, R. S., Griffith, G. C., Meehan, J. P., Zinn, W. J., and Dimitroff, S. P. (1951). A diagnostic pulmonary artery pulse pressure contour in patent ductus arteriosus found during cardiac catheterization. Amer. J. med. Sci., 222, 46.

Liggins, G. C., and Phillips, L. I. (1963). Rubella embryopathy. Brit. med. J., 1, 711.

Loehr, H., Loogen, F., and Vieten, H. (1961). Peripheral pulmonary stenosis. Fortschr. Röntgenstr., 94, 285.

Luan, L. L., D'Silva, J. L., Gasul, B. M., and Dillon, R. F. (1960). Stenosis of the right main pulmonary artery. Circulation, 21, 1116.

Maugars, A. (1802). Description d'une artère pulmonaire considérable, naissant de l'aorte abdominale. Rec. périod. Soc. Méd. Paris., 13, 74.

Møller, P. (1922). Studien über embolische und autochthone Thrombose in der Arteria pulmonalis. Beitr. path. Anat. allg. Path., 71, 27.

Möller, T. (1953). A case of peripheral pulmonary stenosis. Acta. paediat. (Uppsala), 42, 390.

Morrow, A. G., Waldhausen, J. A., Peters, R. L., Bloodwell, R. D., and Braunwald, E. (1959). Supravalvular aortic stenosis. Circulation, 20, 1003.

Oppenheimer, E. H. (1938). Partial atresia of the main branches of the pulmonary artery occurring in infancy and accompanied by calcification of the pulmonary artery and aorta. Bull. Johns Hopk. Hosp., 63, 261.

Powell, M. L., and Hiller, H. G. (1955). Pulmonary coarctation. Med. J. Aust., 1, 272.

Saphir, O. (1932). Bands and ridges in the pulmonary artery. Their relation to Ayerza's disease. Arch. Path., 14, 10.

Sauvage, L. R., Rudolph, A. M., and Gross, R. E. (1960). Replacement of the main pulmonary artery bifurcation by autogenous pericardium. J. thorac. cardiovasc. Surg., 40, 56.

Schwalbe, E. (1909). Die Morphologie der Missbildungen des Menchen und der Tiere, p. 426. Jena.

Shumacker, H. B., and Lurie, P. R. (1953). Pulmonary valvulotomy. Description of a new operative approach. J. thorac. Surg., 25, 173. 
Skoda, J. (1855). Demonstration eines Falles von Obliteration der Aorta. Wochenbl. Z. Ges. Aerzte Wien., 1, 720.

Smith, W. G. (1958). Pulmonary hypertension and a continuous murmur due to multiple peripheral stenoses of the pulmonary arteries. Thorax, 13, 194.

Søndergaard, T. (1954). Coarctation of the pulmonary artery. Danish med. Bull., 1, 46.

Taybi, H., Petry, E. L., Merritt, A. D., Palmer, C. G., Helmen, C. H., and Campbell, J. A. (1963). Congenital supravalvar aortic stenosis and associated pulmonary vascular anomalies. Scientific exhibit, Medical Genetics Programme, Indiana University, Indianapolis, Indiana.

Thrower, W. B., Abelmann, W. H., and Harken, D. E. (1960). Surgical correction of coarctation of the main pulmonary artery. Circulation, 21, 672.

Van Epps, E. F. (1957). Primary pulmonary hypertension in brothers. Amer. J. Roentgenol., 78, 471.

Waldhausen, J. A., Lombardo, C. R., and Morrow, A. G. (1959). Pulmonic stenosis due to compression of the pulmonary artery by an intrapericardial tumor. J. thorac. Surg., 37, 679.

Weinberg, M., Agustsson, M. H., D’Cruz, I. A., Bicoff, J. P., Behravesh, M., Raffensperger, J. G., and Fell, E. H. (1964). Stenosis of the branches of the pulmonary artery. J. thorac. cardiovasc. Surg., 47, 40.

Williams, C. B., Lange, R. L., and Hecht, H. H. (1957). Postvalvular stenosis of the pulmonary artery. Circulation, 16, 195 .

Williamson, D. A. J. (1964). Supravalvar aortic stenosis associated with mental and physical retardation and a characteristic facies. Proc. roy. Soc. Med., 57, 118. 